\title{
Artigos
}

\section{Experiências de médicos brasileiros em seus primeiros meses na Atenção Primária à Saúde na Terra Indígena Yanomami}

\author{
Experiences of Brazilian doctors in their first months of Primary Health Care in \\ the Yanomami Indigenous Land (abstract: p. 18)
}

\section{Experiencias de médicos brasileños en sus primeros meses en la Atención Primaria de la Salud en la Tierra Indígena Yanomami (resumen: p. 18)}

\author{
Fernanda Pereira de Paula Freitas ${ }^{(a)}$ \\ <fernandappfreitas@gmail.com> \\ Willian Fernandes Luna(b) \\ <willianluna@gmail.com> (iD \\ Luiz Otávio de Araujo Bastos ${ }^{(c)}$ \\ <luizotavio.bastos@gmail.com> \\ Bruna Teixeira Ávila ${ }^{(\mathrm{d})}$ \\ <avilatbruna@gmail.com>
}

\author{
(a) Faculdade de Medicina, \\ Universidade Federal do Rio de \\ Janeiro. Rua Aloísio da Silva \\ Gomes, 50, Bairro Granja dos \\ Cavaleiros. Macaé, RJ, Brasil. \\ 27930-560. \\ (b) Departamento de Medicina, \\ Universidade Federal de São \\ Carlos. São Carlos, SP, Brasil. \\ (c) Hospital Universitário Getúlio \\ Vargas, Universidade Federal do \\ Amazonas. Manaus, AM, Brasil. \\ (d) Escola Multicampi de Ciências \\ Médicas, Universidade Federal \\ do Rio Grande do Norte. Caicó, \\ RN, Brasil.
}

O Programa Mais Médicos ampliou o acesso à assistência médica nos contextos indígenas brasileiros, como na Terra Yanomami (TY). Até novembro de 2018, na TY havia exclusivamente médicos cubanos, quando foram substituídos por brasileiros. Esta pesquisa qualitativa buscou compreender as experiências desses médicos brasileiros em seus primeiros meses de trabalho. Realizou-se análise temática dos conteúdos provenientes de entrevistas semiestruturadas, tendo como fio condutor os princípios da Atenção Primária à Saúde (APS) e como referenciais teóricos o saber da experiência e as políticas de saúde indígena. Emergiram três categorias relacionadas ao cuidado em saúde indígena: processo de trabalho, encontro entre culturas e formação médica. As experiências mostraram-se complexas e heterogêneas, com demonstração de satisfação e aprendizados. Conclui-se que o cuidado em saúde indígena demanda um olhar singular e diferenciado para os princípios da APS, devendo-se construir competências para atuação médica nesse contexto.

Palavras-chave: Saúde de populações indígenas. Atenção Primária à Saúde. Médicos. Programa Mais Médicos. 


\section{Introdução}

A Conferência de Alma-Ata em 1978 defendeu o papel central da Atenção Primária à Saúde (APS) para garantia de direitos e na redução das desigualdades, declarando como responsabilidade de todos os governos formular políticas e estratégias para lançar e sustentar os cuidados primários de saúde em coordenação com outros setores ${ }^{1}$. Todavia, a saúde pública brasileira tem vivenciado historicamente escassez de médicos na APS, levando à criação do Programa Mais Médicos (PMM) em 2013² como uma resposta para o provimento médico.

$\mathrm{Na}$ Amazônia Legal, região assistida frequentemente por modelos campanhistas e emergenciais ${ }^{3}$, o PMM possibilitou aumento significativo no número de médicos e consequente melhoria do acesso ao atendimento médico nos Distritos Sanitários Especiais Indígenas (DSEI $)^{4}$. Esses médicos deveriam receber visitas periódicas de supervisores acadêmicos de instituiçôes supervisoras locais, porém a dificuldade de acesso a parte dos territórios, destacando-se várias áreas indígenas, resultou na ausência de supervisão no primeiro ano do $\mathrm{PMM}^{5}$. Dessa forma, em 2015, foi criado pelo Ministério da Educação o Grupo Especial de Supervisão (GES) para acompanhamento pedagógico desses médicos ${ }^{6}$. Em Roraima, os autores deste artigo fizeram parte do GES como supervisores e/ou tutores, com foco na educação permanente relacionada ao processo de trabalho e às competências para atuação na saúde indígena nos DSEI Leste e DSEI Yanomami e Ye’kuana (DSEIY) 5 . Um dos autores também foi médico vinculado ao PMM no DSEIY.

Os princípios da APS foram classicamente descritos por Starfield ${ }^{7}$ em quatro atributos essenciais (acesso de primeiro contato, integralidade, longitudinalidade e coordenação) mais três derivados (orientação familiar, orientação comunitária e competência cultural). No Brasil, as políticas públicas na APS foram desenvolvidas vagarosamente, desde a Conferência de Alma-Ata até a atual Estratégia Saúde da Família, contando com vários dispositivos.

No caso das políticas públicas para os povos indígenas, o avanço também foi lento e paulatino, culminando com a criação do Subsistema de Atenção à Saúde Indígena (SASI-SUS) em 1999, por meio da Lei Arouca (n. 9.836/99) ${ }^{8}$. Assim foram propostos os DSEI para prestar os cuidados de APS, com equipes multidisciplinares de saúde indígena (EMSI) vinculadas aos polos-base e com apoio de profissionais do Núcleo de Apoio à Saúde Indígena. Os níveis de atenção secundário e terciário devem ser garantidos pelos estados e municípios.

A APS nos contextos indígenas possui diretrizes descritas na Política Nacional de Saúde dos Povos Indígenas (PNSPI) ${ }^{9}$, focadas na interculturalidade e no conceito de atenção diferenciada, por meio da adequação de tecnologias e profissionais às especificidades locais ${ }^{10}$. Contempla ainda a diversidade e a superação dos fatores que tornam essa população mais vulnerável aos agravos à saúde, reconhecendo a eficácia de sua medicina e o direito à sua cultura ${ }^{4}$, apesar de na prática ainda apresentar vários desafios e contradiçốes a serem compreendidos e superados ${ }^{11}$.

Ressalta-se que o DSEIY já existia desde 1991, coincidindo com a demarcação da Terra Indígena Yanomami (TY) e com a epidemia avassaladora de malária na região, em grande parte consequente à entrada maciça de garimpeiros no território no fim dos 
anos $1980^{12}$. Em 2017, a população atendida pelo DSEIY era de mais de 25 mil pessoas na TY, das etnias Yanomami e Ye'kuana, em cerca de 320 comunidades nos estados de Roraima e Amazonas (figura 1). Naquele ano, havia 67 EMSI responsáveis pela APS nas aldeias, compostas por 460 profissionais contratados por uma organização social e 14 médicos vinculados ao $\mathrm{PMM}^{(\mathrm{e})}$.

\section{Distrito Sanitário Especial Indígena Yanomami e Ye'kuana Setor de Epidemiologia e Estatística Mapa do Distrito por Pólo-Base}

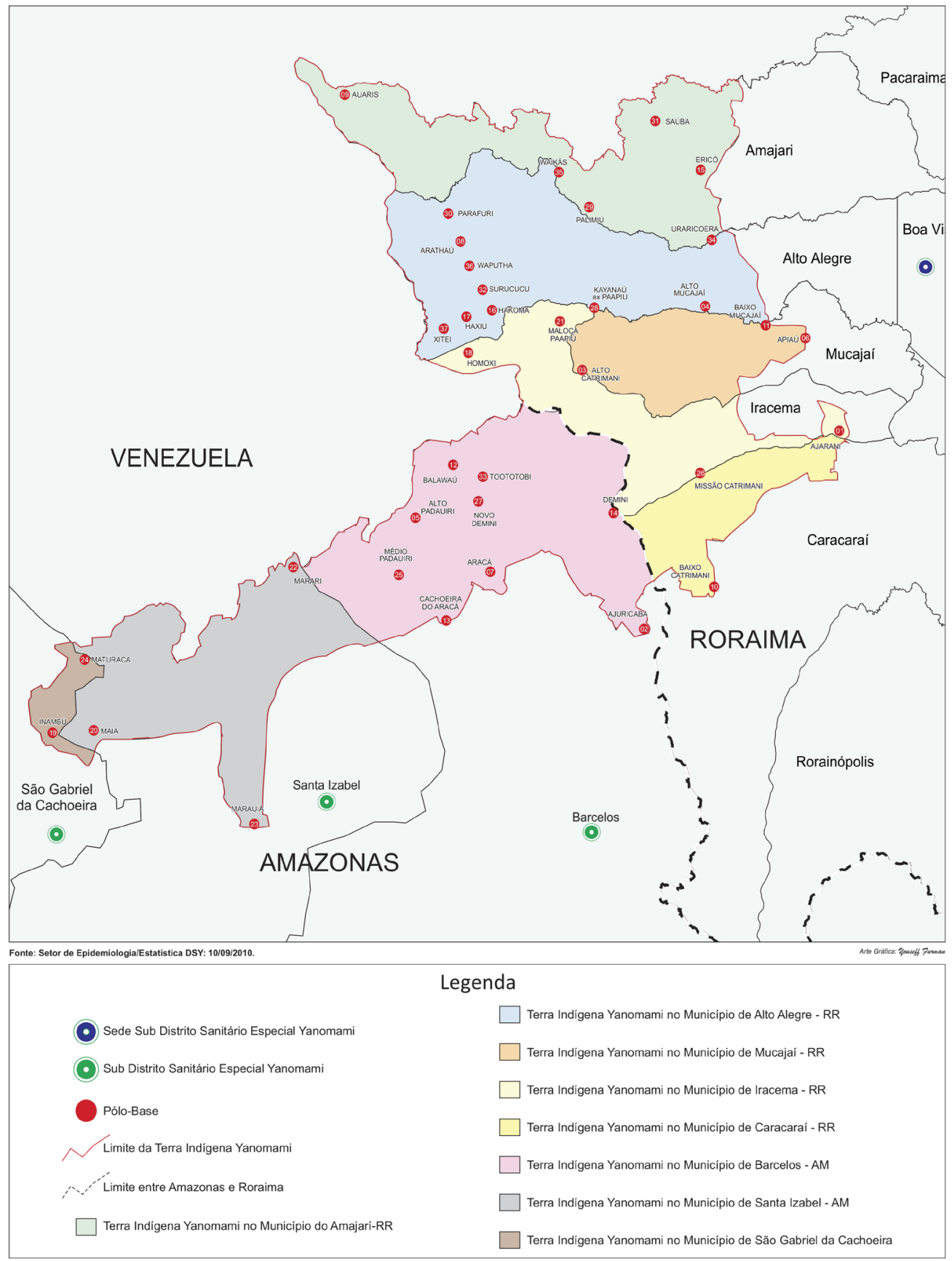

Figura 1. Mapa do Distrito Sanitário Especial Indígena Yanomami e Ye'kuana.

Fonte: Setor de Epidemiologia e Estatística - Distrito Sanitário Especial Indígena Yanomami e Ye'kuana. Boa Vista, Roraima; 2010 (e) Dados fornecidos pela equipe de Epidemiologia do DSEIY. 
Até novembro de 2018, todos os médicos do PMM que atuaram no DSEIY eram cubanos. Com o fim da cooperação internacional entre Brasil, Organização Pan-Americana de Saúde e Cuba, todas as vagas foram ocupadas por brasileiros, trazendo à tona novas relaçóes e desafios. Dessa forma, esta pesquisa teve o objetivo de compreender como foram as experiências dos médicos brasileiros em seus primeiros meses de trabalho no cuidado na APS no DSEIY, analisando desafios e potencialidades neste contexto.

\section{Método}

Realizou-se uma pesquisa exploratória, com abordagem qualitativa, buscando trabalhar com uma compreensão da realidade voltada aos significados e às subjetividades, no sentido da descoberta de seus códigos sociais a partir das falas, em um campo marcado pela especificidade e diferenciação ${ }^{13}$. Tal escolha buscou o exercício do olhar atento e a desconstrução da ideia de neutralidade, já que todos os pesquisadores envolvidos no processo exerceram alguma função na saúde indígena relacionada ao DSEIY.

Para a construção de dados, realizaram-se entrevistas individuais com 18 dos 20 médicos vinculados ao PMM que atuaram no DSEIY em 2019. Optou-se pelo uso de entrevistas semiestruturadas para possibilitar que o entrevistado discorresse sobre o tema, sem se restringir à indagação formulada ${ }^{13}$. As perguntas cursaram sobre a experiência de atuação na saúde indígena, utilizando-se o conceito de experiência como "o que nos passa, o que nos acontece, o que nos toca" ${ }^{14}$ (p. 21), ou seja, não o que se passa, mas o que gera transformação no sujeito que a vive, segundo Larrosa Bondía ${ }^{14}$.

Os participantes foram sete mulheres e 11 homens; possuíam idades entre 25 e 53 anos; nove se autodeclararam brancos, sete pardos e dois negros; nove com graduação em Medicina realizada no Brasil e nove no exterior, com conclusão do curso entre 2014 e 2018; e com período de trabalho no DSEIY de dois a nove meses.

Os materiais oriundos das entrevistas foram submetidos à leitura exaustiva, com construção de mapas conceituais ${ }^{15}$ para a visualização dos conteúdos trazidos pelos sujeitos e com a emergência das pré-categorias de análise.

Realizou-se análise temática de conteúdo na perspectiva de Gomes ${ }^{16}$. Os documentos foram ordenados, os materiais foram decompostos e identificaram-se núcleos de sentido que atravessaram os cenários do cuidado à saúde indígena vivenciado pelos médicos. Finalizou-se com a elaboração de síntese interpretativa, permitindo o diálogo dos eixos identificados com as experiências dos médicos, os objetivos e as questóes iniciais da pesquisa. Neste processo, foram fundamentais os procedimentos para valorizar, compreender, interpretar e articular os dados empíricos com a teoria, para que nascessem reflexôes mais consistentes sobre a realidade em questão ${ }^{13}$.

As categorias temáticas foram construídas e discutidas tendo como fio condutor os princípios da $\mathrm{APS}^{9}$ e, complementarmente, referenciais teóricos sobre o saber da experiência ${ }^{14} \mathrm{e}$ as políticas de saúde indígena.

Esta pesquisa foi aprovada pelo Comitê de Ética em Pesquisa da Universidade Federal de São Carlos sob CAAE 17995819.9.0000.5504. Neste texto, todos os nomes originais foram substituídos para garantir o sigilo dos participantes. 


\section{Resultados e discussão}

Emergiram da análise três categorias temáticas relacionadas ao cuidado em saúde: Processo de trabalho; Encontro entre diferentes culturas; e Formação para e na saúde indígena.

\section{Categoria 1 - Processo de trabalho}

Esta primeira categoria traz as experiências dos médicos em meio ao processo de trabalho no cuidado aos indígenas. Os núcleos de sentido desenvolvidos foram: relaçôes entre APS e Urgência e Emergência (UE); questóes logísticas e de infraestrutura; e relaçôes interpessoais.

No processo de trabalho dos médicos surgiram conflitos quanto à identidade das práticas de cuidado desenvolvidas, trazendo questionamentos sobre o papel da APS:

Todos os medicamentos e materiais que eles mandam para área são para prevenção, para Atenção Primária. Mas sempre tem uns casos graves, como acidente ofídico. Um trauma que eles levam porque caiu da árvore ou que se cortou com a flecha. E aí você acaba tendo que ter um material para poder dar uma assistência. (Carlos)

De acordo as diretrizes do SASI-SUS, os DSEI desenvolvem ações no âmbito da APS, devendo se dedicar aos cuidados essenciais de saúde, sobretudo nos problemas mais frequentes apresentados pelas pessoas, especialmente em suas fases iniciais, e na prevenção e promoção da saúde ${ }^{7,9}$. Para Carlos, há certa confusão sobre o papel das equipes na saúde indígena, pois descola da APS as açôes de urgência, as quais necessitariam de atendimento em outros níveis de atenção. No entanto, nas comunidades indígenas, as demandas incluem frequentemente os atendimentos de UE, o que confunde os profissionais ao transporem os modelos urbanos de cuidado em saúde para aquele cenário:

Onde eu trabalho não é uma unidade básica de saúde, mas é um pronto atendimento. Eu faço coisas que em nenhum outro posto de qualquer cidade se faz. Lá eles têm como encaminhar, tem coisas que nós não temos, desde uma simples comunicação com qualquer outro colega ou internet. (Jorge)

Pelos princípios da APS e pela PNSPI, as EMSI devem garantir o acesso de primeiro contato, isto é, devem ser identificadas como o primeiro recurso a ser buscado, também chamado de "porta de entrada" no sistema de saúde 7 o que inclui a UE para as EMSI. Todavia as relaçóes com os outros níveis de atenção se apresentaram frágeis na TY, sendo difícil a garantia de encaminhamento para outro nível de atenção devido às dificuldades de comunicação via rádio, à distância dos centros de referência e ao transporte. Por esse motivo, as limitaçôes encontradas para a efetivação do cuidado neste território geraram insegurança e medo: 
Área indígena é bem distante mesmo e, por conta disso, acho que fica pouco assistida. Faltam algumas coisas a mais, porque a gente não faz apenas o atendimento básico. A gente faz um atendimento de urgência e emergência. (Gustavo)

Essa complexidade de situações trouxe a necessidade de reorganização do ambiente de saúde como destacado por Vânia, trazendo um exemplo de internação no ambiente da APS:

A estratégia de superar essa dificuldade de seguimento é a internação do paciente lá no setor e acompanhá-lo de perto para ele tomar remédio na hora certa. Foi uma adaptação. (Vânia)

Alguns médicos defenderam que os materiais fornecidos deveriam ser compatíveis com as internaçóes e os atendimentos de UE que realizavam, o que muitas vezes não acontecia:

Eu fiz um parto e não tinha uma pinça, não tinha uma tesoura [...] e não tinham materiais de primeiros socorros, como ambu. Às vezes, falta até oxigênio. (Daniela)

Daniela e outros entrevistados referiram também dificuldades para a assistência universal pelas limitaçôes na disponibilidade de medicamentos e insumos:

Tem pouquíssimas medicações. Você pensa em uma medicação e não tem [...], não temos nada em mãos. Não tem um antibiótico. (Daniela)

Assim, algumas condiçóes eram decisivas no desabastecimento, destacando-se a restrição de itens na Relação de Medicamentos de Atenção Básica para a Saúde Indígena; a insatisfatória logística de distribuição e fornecimento de itens médicos; e um uso abusivo e irrestrito de algumas medicações, especialmente antibióticos e anti-inflamatórios:

É importantíssimo falar da questão da dispensação de antibióticos de forma totalmente irracional em área indígena. Uma coisa é numa epidemia de amebíase afrouxar a mão no secnidazol, metronidazol, porque realmente tem algum substrato teórico no que você está pensando. Outra coisa é um open bar de ceftriaxona, de amoxicilina, sem indicação, para uma população já vulnerável. Isso para mim é um crime! (Sandro)

Esse uso, além de esvaziar o estoque, poderia gerar riscos aos indígenas, como indução de resistência bacteriana e efeitos adversos indesejáveis, como questionado por Bárbara:

[...] eu sinto que, às vezes, com esse excesso de medicação, a gente faz mais mal do que bem, sabe? Eu não acho que faz sempre bem a nossa presença. (Bárbara) 
Algumas vezes esse uso irracional foi justificado pelos profissionais pela dificuldade de continuidade do cuidado, o que relacionaram à localização difusa das comunidades, à alta rotatividade dos profissionais e às escalas das equipes, alternando períodos de trabalho e de folga. Isso, aliado ao foco em açóes emergenciais, prejudica a melhoria dos indicadores na saúde indígena ${ }^{17}$. Assim, em relação à longitudinalidade como atributo da APS - que implica na existência de uma fonte regular de atenção e em seu uso ao longo do tempo, independentemente da presença de problemas específicos relacionados à saúde, estabelecendo-se vínculo e confiança ${ }^{7}$-, percebe-se que ela necessita de outros contornos na saúde indígena, como trouxe Gustavo:

A gente fica muitos dias em área, mesmo assim, é complicado porque nós, médicos, não ficamos apenas em uma região. Talvez eu demore seis meses para voltar para aquela região. (Gustavo)

Nessa dinâmica, os prof issionais conviviam em área durante vários dias, o que tornava as relaçóes interpessoais intensas. Alguns entrevistados contestaram o excesso de autonomia dos enfermeiros na tomada de decisóes em área indígena, justificado pelo fato de, historicamente, estarem habituados a trabalhar em equipes sem médico. Essa expectativa de ser líder da equipe é chamada por Starfield de "modelo delegado", quando a responsabilidade legal é claramente do médico ${ }^{7}$. $\mathrm{Na}$ saúde indígena, esse modelo não necessariamente é o mais comum, nem o mais eficaz. Outros profissionais tendem a ter mais experiência que os médicos nos territórios assistidos, menor rotatividade entre os polos-base, maior carga horária e, geralmente, mais vivência em área indígena.

Os profissionais da saúde indígena devem receber capacitação adequada para o trabalho interdisciplinar de acordo com realidade local' ${ }^{9}$. No entanto, os profissionais não indígenas usualmente se mostram desqualificados para atuarem em contextos interétnicos muito heterogêneos ${ }^{18}$, como apontou Sandro:

Foi assustador ver que as pessoas que trabalham ali defendem a extinção dos indígenas e do meio de vida deles. (Sandro)

As condiçốes de trabalho, alimentação, moradia, saneamento e manutenção de barcos e de aeronaves foram problemas estruturais relacionados ao cuidado em saúde apontados como capazes de provocar riscos à saúde dos trabalhadores:

[...] as missões são feitas todas de barco e, muitas vezes, sem segurança nenhuma. A vida de nós profissionais está em risco. Esse mês teve um avião que parou no ar. E de repente continuou. Meu Deus! (Alice)

O isolamento gerado pelo acesso escasso à internet e a outros médicos para discussão de casos foram fatores descritos como geradores de insegurança. $\mathrm{O}$ único meio de comunicação externa na maior parte dos polos-base era a radiofonia, que apresentava falhas de comunicação e de privacidade. 
Um dos precipitadores de conflitos interpessoais foram as remoções, caracterizadas pelo transporte via aéreo de pacientes para um serviço de referência na cidade, quando não há condiçốes de atendimento adequado nos polos-base. Nesses casos, havia uma negociação entre profissional de saúde, gestão, comunidade e paciente, em uma situação em que o cuidado em saúde e os recursos disponíveis entravam em choque, pois os custos da remoção eram elevados, como colocou Flávia:

A tentativa de não remoção dos pacientes por não querer gastar muito é uma preocupação. O DSEI exerce uma pressão porque é caro. Eles praticamente dizem: tentem resolver esses casos em área. E aí como resolver em área? (Flávia)

As relaçôes interpessoais no processo de trabalho também foram apontadas como favorecedoras dos processos de cuidado, tais como: integração interdisciplinar, realização de rodas de conversa com a comunidade e o "amor" na relação de cuidado. A organização de escalas entre os profissionais para divisão das tarefas relacionadas ao trabalho e às responsabilidades domésticas foi, segundo Mário, um aspecto bastante positivo:

[...] o que melhorou a relação foi fazer escalas de cozinha, de atendimento, de quem liga e desliga o motor. [...] Até sobre música alta a gente tem que conversar para não ter problema. (Mário)

Destacou-se ainda em vários relatos a boa receptividade das equipes e dos indígenas, o que favoreceu o comprometimento dos médicos que estavam chegando a estes locais de trabalho.

\section{Categoria 2 - Encontro entre diferentes culturas}

Nesta categoria, são apresentadas as experiências de cuidado dos médicos com foco nas relações com a cultura indígena. Foram destacados três núcleos de sentido: aproximação com o diferente; hierarquia nas relaçóes entre profissionais de saúde e indígenas; e respeito à diversidade.

No encontro entre culturas, destacou-se a vivência do diferente, como descrito por Daniela, demonstrando encantamento:

Eles têm a cultura deles. É outro jeito de viver. Eu fico olhando e converso muito com eles. É um mundo à parte, eu gosto! (Daniela)

A TY abriga cinco línguas oriundas dos povos Yanomami e Ye'kuana, sendo característico neste local o pouco domínio do português. Dessa forma, foi recorrente a dificuldade com a língua desconhecida, exigindo que a relação fosse frequentemente intermediada pela tradução de um agente indígena de saúde e demandando um esforço de observação da linguagem não verbal. Assim, a interação médico-paciente e a identificação adequada dos problemas de saúde das pessoas foram dificultadas, tornando desafiadora a busca pela integralidade. Segundo Starfield, a 
integralidade exige que na APS se reconheça, adequadamente, a variedade completa de necessidades relacionadas à saúde do paciente e se disponibilize os recursos para abordá-las ${ }^{7}$. Nesse contexto, as diferentes línguas e linguagens tornavam mais desafiadora a atenção integral, como relatado por Alice:

É um pouco dificultoso devido ao idioma, é uma barreira. (Alice)

As diferenças na linguagem e cultura influenciavam, ainda, a maneira como as pessoas observavam o tempo e o espaço, como apontou Leandro:

Eles não contam os anos, o que dificulta muito ter uma noção temporal. Eles trabalham com o tempo de uma maneira diferente, em semanas, em luas. Você não consegue ter uma dimensão de tempo ao contarem uma história da doença. (Leandro)

Nesse universo do diferente, algumas palavras locais foram sendo incorporadas pelos médicos, que as utilizaram ao falar de suas experiências, como: hoximi (ser mau, feio), totihi (ser bom, bonito) tuxaua (liderança, cacique) e nabè (pessoa não Yanomami, forasteiro).

Foram identificadas diferenças na maneira como os indígenas percebiam o próprio corpo e experienciavam a doença. Além disso, a objetividade da Biomedicina não era suficiente naquele contexto, sendo necessário relativizar os conhecimentos:

Aqui eu aprendi que dois mais dois não são quatro. Tem paciente que não quer tomar aquela medicação e a gente acha que ele vai a óbito. Mas ele sobrevive. Tem mãe com criança com diarreia que nem leva o soro para casa, mas a criança volta sadia. Eles são muito resistentes! (Daniela)

No relato de Flávia, essa outra forma de experiência de adoecimento e dor também surgiu ao relatar o atendimento de uma criança:

Eu não tinha um diagnóstico preciso. Como ele era muito resistente à dor, ele mexia e fazia os movimentos como se não tivesse fraturado. Só descobri que tinha fratura depois. (Flávia)

Essas diferenças favoreceram reflexões pessoais dos médicos que reconheceram o processo saúde-adoecimento a partir de outros pontos de vista. Nesse sentido, pareceu haver uma superação do modelo baseado na doença para uma compreensão sobre a experiência de adoecimento, ressaltando-se que as produçóes de significado acerca da doença remetem a visões de mundo que, expressas pelo indivíduo singular, são conformadas pela cultura da qual ele toma parte ${ }^{19}$. 
Nessa mudança de olhar, pôde-se reconhecer um novo entendimento sobre a cultura local e familiar e sobre como aquela comunidade vivenciava as práticas de saúde e os processos de adoecimento ou, ainda, a orientação familiar e comunitária - atributo derivado da APS. Dessa forma, para uma análise adequada das necessidades em saúde das pessoas, é necessário conhecimento sobre o contexto social e familiar no qual elas surgem².

Reconhecer as diferentes formas de ver saúde e doença favorece um posicionamento adequado frente às tensôes produzidas no encontro entre médicos e pacientes ${ }^{19}$.

Com uma cultura diferente, algumas coisas mudam, alguns conceitos têm que ser testados um pouco para ver se se adequam àquela realidade. E eles mesmos vão dizer o que não se adéqua ou a equipe vai ver na prática que algumas coisas simplesmente não cabem. (Hélio)

Essa reflexão relativizou a hierarquia do conhecimento, o poder biomédico e o eurocentrismo, colocando o saber dos indígenas em igual importância, refletindo o desenvolvimento de outro atributo derivado da APS, a competência cultural, que envolve o reconhecimento das necessidades especiais das subpopulaçóes que podem não estar em evidência devido a características étnicas, raciais ou outras características culturais especiais?

Entretanto, nem sempre a relação entre médico e indígenas acontecia dessa forma. Alguns indagaram a maneira como o indígena exigia seus direitos, interpretando-a como excessiva, o que novamente trouxe a não horizontalidade na relação:

Alguns querem usufruir do branco e falam: "Eu sou índio e tudo era meu e você tem que me dar". Eles passam um pouco do limite [...]. Eles aproveitam dessa condição para tentar ser o mais branco possível, mas sem deixar de ser índio. Porque ser índio traz muitos benefícios. (Jorge)

Esse questionamento entre identidade e direito traz consigo uma visão estática da cultura, bem como de resquícios da tutela, enfrentada pelos indígenas até a Constituição de 1988. Ou seja, nessa compreensão de Jorge, o indígena teria mais direitos quanto mais próximo do primitivo ele estivesse, em uma visão evolucionista da cultura, desconsiderando sua dinamicidade ${ }^{20}$. A história do contato com o branco (não indígena); a situação de isolamento ou de aldeamento; o fato de frequentar a cidade; e o uso de produtos e mercadorias não indígenas interferem nessa identidade, gerando preconceitos culturais ${ }^{21}$. Pelo relato dos médicos, alguns contatos com as equipes de saúde também afetaram essa relação com os indígenas, ao se reproduzirem relações de dominação:

Eu vou aprendendo esses dois caminhos: o da equipe que é um local de dominação, mas também de uma posição digamos “superior”, assim, entre aspas, porque possui a possibilidade de dar assistência, mas também porque possui produtos e mercadorias diferentes que a comunidade não tem. (Hélio) 
Nesse relato, percebe-se que os produtos levados da cidade para a aldeia seriam ferramentas mantenedoras da relação de dominação e perpetuação da perspectiva tutelar com os indígenas, centralizando os insumos e a tomada de decisões dos não indígenas, o que dificultava a relação horizontal entre profissionais de saúde e população.

$\mathrm{Na}$ tentativa de alcançar o respeito em relação à cultura diferente, a empatia parece ser um dos caminhos para o diálogo entre culturas, como trouxe Bárbara:

Eu tento fazer o máximo para tratá-los da melhor forma e entendendo a complexidade que existe nas diferenças culturais. Eu tento estar disponível e me colocar no lugar deles. Ser respeitosa e me apresentar ao tuxaua, porque eu vou viver naquele local. (Bárbara)

Dessa forma, após o estranhamento inicial, as tentativas de respeito e tolerância à diversidade podem ser um primeiro passo para construção compartilhada do cuidado nesses territórios, sendo um desafio apontado em diversas realidades ${ }^{22}$ :

É complicado você saber até onde ir. Com relação ao xabori que eles falam, a pajelança. Eles vão tirar o espírito que causa a doença. Como agir junto com eles? Chegam os pajés e eles começam a fazer o ritual. Talvez seja ignorância minha, mas não sei o que fazer diante daquilo. (Jorge)

A interculturalidade é um possível caminho para essa construção não colonizadora, com reconhecimento de práticas e representações dos sujeitos e grupos, inclusive no uso intencional de itinerários terapêuticos diferentes da Biomedicina ${ }^{23}$.

\section{Categoria 3 - Formação para e na saúde indígena}

As primeiras experiências dos médicos e os desafios encontrados questionaram sua própria formação, ao colocarem na prática os conhecimentos aprendidos. Nesta categoria, surgiram três núcleos de sentido: relações com a formação biomédica, experiências pregressas destacadas e educação permanente na saúde indígena.

A graduação em Medicina tem forte caráter biomédico e, ao mesmo tempo em que essa formação parece ter gerado condiçốes de segurança para a tomada de decisão clínica nas situaçóes de UE, percebeu-se a necessidade de rever preceitos que a eles antes pareciam únicos.

[...] o que me ajudou na Medicina é o que a gente aprendeu mesmo como acadêmico, é a farmacologia, de correr atrás, de olhar o que eu posso substituir uma coisa por outra. (Daniela)

Para ela, o conhecimento biomédico pareceu contribuir com a tomada de decisóes mas, para Gustavo, ajudaria mais "saber tomar condutas mais empíricas, que é uma coisa que a gente acaba fazendo, mas sem formação para isso", evidenciando que a formação 
focada em protocolos não era suficiente para o trabalho diante das especificidades ou da escassez de recursos. Além de não ser suficiente, precisaria ser revista, recriada, como diz Flávia: "Eu várias vezes tive que agir como me disseram para não agir na faculdade".

Apesar dos próprios indígenas reconhecerem resolutividade na Biomedicina, identificam-se limites quanto à sua efetividade em determinados contextos ${ }^{24}$. Nesse âmbito, o estudo das Ciências Sociais, especialmente da Antropologia, foi relatado como importante para a atuação no contexto da saúde indígena.

As Diretrizes Curriculares Nacionais (DCN) dos cursos de Medicina apontam para a formação humanista crítica e reflexiva, para a inserção cada vez mais precoce nos mais diversos cenários na saúde pública, especialmente na APS, e para a importância de ser considerada a diversidade humana e cultural em seus vários contextos a partir do diálogo com outras disciplinas ${ }^{25}$.

Esse processo parece ter influenciado positivamente a formação dos entrevistados que fizeram graduação no Brasil a partir do contato prévio com a saúde pública em cenários diversos, como referiu Bárbara: "eu acho que a instituição ajudou muito, assim, de entender a saúde pública, foi algo que me auxiliou muito a tomar essa decisão".

Nesse sentido, os aprendizados nos serviços de APS podem favorecer a atuação desses profissionais por se reconhecerem enquanto coordenação do cuidado, descrito como uma adequada e eficiente troca de informaçóes para que as pessoas possam receber o cuidado em saúde, inclusive nos casos de referência e contrarreferência ${ }^{7}$.

As DCN reconhecem a necessidade de discussóes que envolvam o universo das diferenças étnico-raciais durante a graduaçãa ${ }^{25}$, porém, não tratam exatamente da questão indígena. Dessa forma, não conseguiram ainda refletir mudanças nos cursos, gerando fragilidade ou muitas vezes ausência de formação específica para a saúde indígena, como relatou Tatiana:

Eu vim de uma federal e lá não tem nenhuma base dentro do currículo que ajuda quanto a isso. Mesmo a gente tendo território com várias terras indígenas. (Tatiana)

Experiências na graduação, com aproximações ao universo indígena mediante a imersão na cultura local, podem favorecer os estudantes da área da Saúde à superação do imaginário romântico, compreendendo processos históricos de exclusão das políticas públicas, além do desenvolvimento de respeito e valorização de saberes tradicionais ${ }^{26}$. No entanto, essa formação dificilmente acontece, como apontado pelas falas, mesmo para os formados fora do Brasil, incluindo países com forte presença da população indígena, como a Bolívia. É importante considerar também a grande diversidade dos povos indígenas e dos seus territórios. Alice contou que se formou no Paraguai e, mesmo com pouco contato com os indígenas naquele local, cuja maioria da população era guarani, o que faltou foi o preparo clínico para as endemias:

[...] no Paraguai não tem malária. Então eu estudei isso bem superficial e aqui está lotado. (Alice) 
Foram favorecedores do trabalho dos médicos no contexto indígena o contato prévio com populações tradicionais, mesmo que não indígenas ${ }^{27}$, além de experiências fora da cidade e com escassez de recursos:

$\mathrm{Na}$ minha formação eu senti falta de emergências nesses cenários rurais, nesses contextos isolados. [...]. Eu tive estágio rural e pude desenvolver um pouco essas habilidades de competência cultural, foi quando abri o olho pra isso. (Hélio)

Outros ponderaram que a experiência em área rural não era suficiente, já que são realidades distintas, apesar de algumas aproximaçóes relatadas por Leandro:

A gente teve uma banca de saúde rural, que eu considero que foi a coisa mais semelhante que a gente teve com saúde indígena. Tinha que trabalhar com poucos insumos e com distâncias maiores. Só que não é a mesma coisa. Não dá para falar que é só saúde rural, porque não é. (Leandro)

A quarta Conferência Nacional de Saúde Indígena recomendou a inclusão dos conteúdos sobre Saúde Indígena nos currículos de formação técnica e superior em saúde, mas isso não foi efetivado na grande maioria dos cursos, o que gera invisibilidade sobre a saúde desses povos ${ }^{28}$. Dessa forma, a formação dos profissionais que atuam na saúde indígena acaba sendo realizada apenas depois de adentrarem no serviço, sendo importante criar formas de educação permanente que deem conta desse cenário, o que também foi recomendação da Conferência ${ }^{18}$.

Um curso introdutório sobre Antropologia, promovido pela gestão do DSEIY a todos os profissionais, conforme previsto na PNSPI, trouxe um contato com a cultura dos povos da TY, como relatado por Daniela: "A única coisa que eu fiz foi o curso de Antropologia. Me ajudou bastante".

Porém, a formação foi vista como pontual e insuficiente, principalmente diante da complexidade do trabalho e da ausência de contato anterior com essas temáticas durante a graduação, como afirmaram Jorge e Hélio:

Aquele curso devia ser bem mais aprofundado [...]. Acho que foram vinte horas. E faltou, porque ali muita coisa a gente não esperava. (Jorge)

Eu nunca tinha tido discussão nenhuma sobre isso, nada de Antropologia, de outras áreas, das ciências sociais da saúde. (Hélio)

No encontro com o diferente e com os limites da Biomedicina, torna-se necessário o diálogo com outras ciências. Todavia, as formaçôes para os profissionais da saúde indígena têm sido descontinuadas e orientadas pelos programas do Ministério da Saúde, e não pela realidade local ${ }^{18}$. 
A experiência de aprendizado ao longo do tempo foi trazida pelos médicos, desenvolvendo segurança no cotidiano das práticas em saúde nas aldeias, o que demonstra a construção do saber da experiência, na relação entre conhecimento e vida humana ${ }^{14}$. Desse modo, as lacunas deixadas na graduação deveriam ser preenchidas pelo aprendizado cotidiano e específico da educação permanente. Ou seja, como as especificidades são muito singulares, elas tornam-se imprevisíveis e o processo de ação-reflexão-ação deve surgir para os problemas encontrados na vida prática ${ }^{29}$, com construção de novas ferramentas para um cuidado voltado à atenção diferenciada e de acordo com os princípios da APS.

\section{Considerações finais}

As experiências de médicas e médicos brasileiros nos primeiros meses de trabalho no DSEIY se mostraram complexas e heterogêneas, com demonstração de satisfação e aprendizado.

Os profissionais enfrentaram uma diversidade de desafios relacionados ao processo de trabalho, destacando-se a alta rotatividade dos médicos; conflitos identitários entre APS e UE; fragilidades de infraestrutura e logística; e fortalecimento da atuação profissional a partir das relaçóes interpessoais.

O encontro entre esses profissionais e indígenas trouxe encantamentos e aprendizados para a atuação no contexto de saúde local, aflorando diferentes compreensões sobre o processo de saúde e adoecimento. A participação dos indígenas na tomada de decisóes em saúde foi apresentada como importante, questionando-se as relaçóes de poder entre profissional de saúde e paciente.

Destacaram-se a ausência de conteúdos sobre saúde indígena na graduação em Medicina e a importância da construção pessoal de aprendizado a partir da experiência e de processos de educação permanente.

Conclui-se que o cuidado em saúde em áreas indígenas demanda um olhar atento para os princípios da APS e que, para isso, é importante considerar a diretriz da atenção diferenciada, já que não se trata de apenas transpor o trabalho realizado na zona urbana, ou em áreas rurais habituais, para o contexto indígena. Também não se trata de simplesmente aplicar o que é ensinado nas graduaçôes em Medicina, já que a saúde indígena não faz parte dos currículos. Trata-se de se construir competências para atuação no contexto indígena a partir da prática para atingir o direito à saúde dessas populaçóes. 


\section{Contribuições dos autores}

Todos os autores participaram ativamente de todas as etapas de elaboração da pesquisa e do manuscrito.

\section{Agradecimentos}

Agradecemos às pessoas entrevistadas, que conosco dividiram suas angústias e incertezas; às outras profissionais das EMSI - em especial, agentes indígenas de saúde e técnicos e técnicas de enfermagem - pelas histórias, comidas e trabalhos compartilhados; e, por fim, aos povos Yanomami e Ye'kuana, pelos seus médicos tradicionais que seguem firme disputando, ensinando e trabalhando em conjunto com os profissionais de saúde não indígenas.

\section{Conflito de interesse}

Os autores não têm conflito de interesse a declarar.

\section{Direitos autorais}

Este artigo está licenciado sob a Licença Internacional Creative Commons 4.0, tipo BY (https://creativecommons.org/licenses/by/4.0/deed.pt_BR).

(cc) BY

\section{Editora}

Denise Martin

Editora associada

Cristina Larrea Killinger

Submetido em

27/04/20

Aprovado em

$26 / 11 / 20$

\section{Referências}

1. Organização Mundial da Saúde. Declaração de Alma-Ata. Conferência Internacional sobre Cuidados Primários de Saúde. Alma-Ata, URSS; 6-12 de setembro de 1978. Alma-Ata: OMS; 1978.

2. Lei no 12.871 , de 22 de Outubro de 2013. Institui o Programa Mais Médicos, altera as Leis no 8.745, de 9 de Dezembro de 1993, e no 6.932, de 7 de Julho de 1981, e dá outras providências. Diário Oficial da União. 23 Out 2013.

3. Souza ABL. Construção de uma rede de serviços no interior do Amazonas: a experiência do SESP e da FSESP. In: Schweickard TJC, Ferla AA, Lima RTS, Kadri MR, organizadores. História e política pública de saúde na Amazônia. Porto Alegre: Rede UNIDA; 2017. p. 43-70. 
4. Fontão MAB, Pereira EL. Projeto Mais Médicos na saúde indígena: reflexões a partir de uma pesquisa de opinião. Interface (Botucatu). 2017; 21(1):1169-80.

5. Luna WF, Ávila BT, Brazão CFF, Freitas FPP, Cajado LCS, Bastos LOA. Projeto Mais Médicos para o Brasil em áreas remotas de Roraima, Brasil: relações entre médicos e Grupo Especial de Supervisão. Interface (Botucatu). 2019; 23(1):1-14.

6. Portaria Normativa no 28, de 14 de Julho de 2015. Dispõe sobre a criação e organização do Grupo Especial de Supervisão para áreas de difícil cobertura de supervisão, no âmbito do Projeto Mais Médicos para o Brasil, e dá outras providências. Diário Oficial da União. 14 Jul 2015.

7. Starfield B. Atenção Primária: equilíbrio entre necessidades de saúde, serviços e tecnologia. Brasília: UNESCO, Ministério da Saúde; 2002.

8. Lei no 9.836, de 23 de Setembro de 1999. Acrescenta dispositivos à Lei no 8.080, de 19 de Setembro de 1990, que "dispõe sobre as condições para a promoção, proteção e recuperação da saúde, a organização e o funcionamento dos serviços correspondentes e dá outras providências”, instituindo o Subsistema de Atenção à Saúde Indígena. Diário Oficial da União. 23 Set 1999.

9. Fundação Nacional de Saúde. Política Nacional de Atenção à Saúde dos Povos Indígenas. Brasília: Ministério da Saúde, FUNASA; 2002.

10. Pontes ALM, Rego S, Garnelo L. O modelo de atenção diferenciada nos Distritos Sanitários Especiais Indígenas: reflexóes a partir do Alto Rio Negro/AM, Brasil. Cienc Saude Colet. 2015; 20(10):3119-210.

11. Ferreira LO. Interculturalidade e saúde indígena no contexto das políticas públicas brasileiras. In: Langdon EJ, Cardoso MD, organizadores. Saúde Indígena: políticas comparadas na América Latina. Florianópolis: UFSC; 2015. p. 217-46.

12. Pithan OA. O modelo Hekura para interromper a transmissão da malária: uma experiência de ações integradas de controle com os indígenas yanomami na virada do século XX [dissertação]. Roraima: Escola Nacional de Saúde Pública Sergio Arouca, Fundação Oswaldo Cruz; 2005.

13. Minayo MCS. Pesquisa social - Teoria, método e criatividade. 33a ed. Rio de Janeiro: Vozes; 2013. p. 9-29.

14. Bondía JL. Notas sobre a experiência e o saber de experiência. Rev Bras Educ. 2002; 19:20-8.

15. Moreira MA. Aprendizagem significativa. Brasília: UnB; 1998.

16. Gomes R. Análise e interpretação de dados de pesquisa qualitativa. In: Minayo MCS, organizador. Pesquisa social - Teoria, método e criatividade. 33a ed. Rio de Janeiro: Vozes; 2013. p. 79-108.

17. Mendes AM, Leite MS, Langdon EJ, Grisotti M. O desafio da atenção primária na saúde indígena no Brasil. Rev Panam Salud Publica. 2018; 42(184):1-6.

18. Diehl EE, Pellegrini MA. Saúde e povos indígenas no Brasil: o desafio da formação e educação permanente de trabalhadores para atuação em contextos interculturais. Cad Saude Publica. 2014; 30(4):867-74.

19. Kleinman A, Eisenberg L, Good B. Culture, illness, and care: clinical lessons from anthropologic and cross-cultural research. Ann Intern Med. 1978; 88(2):251-8.

20. Laraia RB. Cultura, um conceito antropológico. 14a ed. Rio de Janeiro: Jorge Zahar; 2004. 
21. Dalmonego C. "Paeterepë: quem são esses napëpë?” Elementos para o estudo da construção Yanomami da alteridade dos missionários [dissertação]. São Paulo: Pontifícia Universidade Católica de São Paulo; 2015.

22. Luna WF, Bastos LOA, Freitas FPP, Ávila BT. Conflito, respeito e construção intercultural: o encontro entre diferentes culturas na atuação dos médicos com os Yanomami. In: Heufemann NEC, Ferla AA, Lima KMS, Martins FM, Lemos SM, organizadores. Saúde Indígena: educação, gestão e trabalho. Porto Alegre: Rede UNIDA; 2020. p. 147-66.

23. Menéndez E. Intencionalidad, experiencia y función: la articulación de los saberes médicos. Rev Antropol Soc. 2006; 14:33-69.

24. Pereira PPG. Limites, traduções e afetos: profissionais de saúde em contextos indígenas. Mana. 2012; 18(1):511-38.

25. Brasil. Ministério da Educação. Conselho Nacional de Educação. Câmara de Educação Superior. Diretrizes Curriculares Nacionais do Curso de Graduação de Medicina. Brasília: Ministério da Educação; 2014.

26. Luna WF, Nordi ABA, Rached KS, Carvalho ARV. Projeto de Extensão Iandé Guatá: vivências de estudantes de Medicina com indígenas Potiguara. Interface (Botucatu); 2019; 23:e180576.

27. Martins AC, Schlosser AR, Arruda RA, Klein WW, Andrade BWB, Labat ALB, et al. Ensino médico e extensão em áreas ribeirinhas da Amazônia. Rev Bras Educ Med. 2013; 37(4):566-72.

28. Fundação Nacional de Saúde. Relatório final da 4a Conferência Nacional de Saúde Indígena. Brasília: Fundação Nacional de Saúde; 2007.

29. Brasil. Ministério da Saúde. Secretaria de Gestão do Trabalho e da Educação na Saúde. Departamento de Gestão da Educação na Saúde. Política Nacional de Educação Permanente em Saúde: o que se tem produzido para o seu fortalecimento? Brasília: Ministério da Saúde; 2018. 
The More Doctors Program expanded access to medical care in the Brazilian indigenous contexts, as in the Yanomami Land (TY). This qualitative research sought to understand the experience of the Brazilian doctors in the TY in their first months of work since November 2018. The research conducted a thematic analysis of the contents from semi-structured interviews, having as its common thread the principles of Primary Health Care (PHC) and as theoretical frameworks, experiential knowledge and indigenous health policies. Three categories related to indigenous health care emerged: work process; encounter between cultures; medical training. The experience proved to be complex and heterogeneous, demonstrating satisfaction and learning. The study concludes that indigenous health care demands a singular and differentiated outlook at the principles of PHC, and that competencies for medical practice in this context must be built.

Keywords: Health of indigenous populations. Primary Health Care. Physicians. More Doctors Program.

El Programa Más Médicos amplió el acceso a la asistencia médica en los contextos indígenas brasileños, como en la Tierra Yanomami (TY). Hasta noviembre de 2018, en la TY había exclusivamente médicos cubanos, cuando fueron substituidos por brasileños. La investigación cualitativa buscó comprender la experiencia de esos médicos brasileños en sus primeros meses de trabajo. Se realizó un análisis temático de los contenidos provenientes de entrevistas semiestructuradas, teniendo como hilo conductor los principios de la Atención Primaria de la Salud (APS) y como referenciales teóricos el saber de la experiencia y las políticas de salud indígena. Surgieron tres categorías relacionadas al cuidado en salud indígena: proceso de trabajo, encuentro entre culturas y formación médica. La experiencia se mostró compleja y heterogénea, con demostración de satisfacción y aprendizaje. Se concluyó que el cuidado en salud indígena demanda una mirada singular y diferenciada para los principios de la APS, siendo necesario construir competencias para la actuación médica en ese contexto.

Palabras clave: Salud de poblaciones indígenas. Atención Primaria de la Salud. Médicos. Programa Más Médicos. 